\title{
Testimonios
}

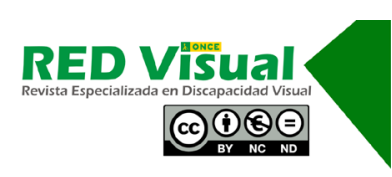

Recepción: 24-02-2021 Aceptación: 22-03-2021

\section{Diario covid}

\section{P. Jiménez Sánchez}

Diez de la mañana, 13 de marzo. Como técnico de rehabilitación me desplazo a un pueblo para comenzar una sesión de orientación y movilidad con un afiliado. Estamos los dos totalmente solos en la calle, no hay nadie en la plaza del pueblo, las cafeterías están vacías al igual que las tiendas, charlamos atónitos sobre la situación tan particular en la que discurre la sesión. Terminamos la clase y acordamos la cita para la próxima semana, sin saber que nunca iba a tener lugar. Al día siguiente se resuelven nuestras dudas, pero llegan otras aún más grandes junto al término estado de alarma. La noticia de que se suspende la venta de cupón me llega como un baño de realidad y me pone los pies en la tierra después de unos días tan particulares. Pasan los días y suben los contagios, los fallecidos y la desesperación por tener unos minutos de mi vida precovid. Se detuvo el cupón, pero no los servicios sociales, y tuvieron más protagonismo que nunca. Comencé las Ilamadas telefónicas a los afiliados, ahora también como voluntaria, para conocer su estado de salud y ánimo, qué necesitan, que no están solos, y la ONCE está ahí por y para ellos. Ha sido duro escuchar como algunos afiliados enterraban a familiares, lloraban conmigo y yo con ellos al otro lado del teléfono. Pero no hay mal que cien años dure, y vemos luz al final del túnel sin saber que este solo era el primer tramo. Volvemos a salir, con miedo, pero vamos hacia delante. Volvemos a vernos, aunque sea con distancia. Vuelve el cupón a la calle, con ello el trabajo, mi rutina, y valoro cada pequeña acción que antes ignoraba y ahora me hace muy feliz. Empezamos la atención con especial hincapié en afiliados cuya situación personal ha cambiado durante estos meses y precisan de autonomía para seguir adelante, y con el trabajo llegan los frutos y una sensación de futuro, de que saldremos de esta y volveremos más fuertes que nunca. Es cierto que esta pandemia nos ha hecho mucho daño, pero con esperanza, trabajo y responsabilidad podremos navegar en estas oleadas de coronavirus, porque no tenemos que tener ninguna 
duda de que todo esto algún día será otra de las muchas historias de superación a lo largo de los años de la ONCE.

\section{Paloma Jiménez Sánchez}

Jiménez, P. (2021). Diario covid. RED Visual: Revista Especializada en Discapacidad Visual, 77, 341-342. https:// doi.org/10.53094/DBDJ5659. 